\title{
Maltreatment in Childhood and Adolescence
}

Results From a Survey of a Representative Sample of the German Population

Winfried Häuser, Gabriele Schmutzer, Elmar Brähler, Heide Glaesmer

\section{SUMMARY}

Background: There are no up-to-date, representative studies on the frequency of maltreatment (abuse or neglect) among children and adolescents in Germany.

Methods: In a cross-sectional study, standardized questionnaires were administered to persons aged 14 and older in a representative sample of the German population. Statistics on maltreatment in childhood and adolescence were collected with the German version of the Childhood Trauma Questionnaire. Regression analysis was used to detect potential associations of maltreatment with demographic variables including sex, age, place of birth, and social class.

Results: 2504 of the 4455 persons contacted (56\%) completed the study. Severe emotional abuse in childhood and/or adolescence was reported by $1.6 \%$ of persons in the overall sample, severe physical abuse by $2.8 \%$, and severe sexual abuse by $1.9 \%$. Severe emotional neglect was reported by $6.6 \%$ and severe physical neglect by $10.8 \%$. Female sex was a predictor for severe sexual abuse, while belonging to a low or middle social stratum was a predictor for severe physical abuse and neglect. Being older at the time of the survey was a predictor for severe physical neglect. All types of maltreatment were significantly correlated with each other $(p<0.001)$.

Conclusion: The frequencies of various types of abuse and neglect of children and adolescents that were retrospectively determined in this up-to-date study by questionnaire of a representative sample of the German population, and the correlations between them, correspond to those found in a German populationbased study in 1995 and in recent American studies.

\section{Cite this as:}

Häuser W, Schmutzer G, Brähler E, Glaesmer H: Maltreatment in childhood and adolescence-results from a survey of a representative sample of the general German population. Dtsch Arztebl Int 2011; 108(17): 287-94.

D0I: 10.3238/arztebl.2011.0287
Klinik für Innere Medizin I (Gastroenterologie, Hepatologie, Stoffwechsel- und Infektionskrankheiten, Psychosomatik), Klinikum Saarbrücken gGmbH und Klinik für Psychosomatische Medizin und Psychotherapie, Technische Universität München: PD Dr. med. Häuser

Abteilung für Medizinische Psychologie und Medizinische Soziologie, Universität Leipzig: Dipl.-Math. Schmutzer, Prof. Dr. rer. nat. Brähler, Dr. phil. Dipl.-Psych. Glaesmer altreatment in childhood and adolescence constitutes a major social problem and a health risk throughout the world (1). In the USA, the Centers for Disease Control and Prevention (CDC) define child maltreatment as "Any act or series of acts of commission or omission by a parent or other caregiver (e.g., clergy, coach, teacher) that results in harm, potential for harm, or threat of harm to a child." Acts of commission are divided into physical, sexual, and psychological abuse. Acts of omission are classified as physical, emotional, medical, or educational neglect or failure to supervise. Neglect is defined as "failure to provide for a child's basic physical, emotional, or educational needs or to protect a child from harm or potential harm," while abuse is "words or overt actions that cause harm, potential harm, or threat of harm to a child." Maltreatment can be characterized in terms of severity (from mild to severe) and frequency (from an isolated occurrence to repeated acts over a number of years) (2).

The frequency of child maltreatment can be estimated from externally registered cases of maltreatment, e.g., cases recorded by the Federal Criminal Police Office or case series from pediatric hospitals. However, this method probably underestimates the true prevalence of child maltreatment because of the high proportion of cases assumed to go unreported (3). Alternatively, the frequency of child maltreatment can be ascertained by retrospective population surveys. Previous studies on the frequency of maltreatment in childhood that have been based on surveys (by questionnaire or interview) of samples of the general population have focused mainly on one type of maltreatment, i.e., sexual abuse (4). To our knowledge, only one study of a representative sample of the population on the frequency of maltreatment in childhood using a questionnaire designed by the investigators has been carried out in Germany to date. This study, conducted in 1992 and published in 1998, surveyed 3289 people aged 16 to 59 years. Of those questioned, $75 \%$ reported experiencing physical violence before the age of 16 and $6 \%$ stated they had been sexually abused (5).

A review of European studies on maltreatment in childhood and adolescence found that sexual abuse was commoner among girls and physical maltreatment more frequent among boys (6). The German study mentioned above revealed an association between social class and physical abuse, but not between class and sexual abuse (5). 
TABLE 1

\section{Demographic characteristics of the sample}

\begin{tabular}{l|l}
\multicolumn{2}{l}{ Sex } \\
Women n (\%) & $1331(53.2)$ \\
\hline Men n (\%) & $1173(46.8)$ \\
\hline $\begin{array}{l}\text { Place of birth } \\
\text { Germany n (\%) }\end{array}$ & $2411(96.3)$ \\
\hline Outside Germany n (\%) & $93(3.7)$ \\
\hline Residence &
\end{tabular}

\begin{tabular}{l|l}
\hline Former West Germany n (\%) & $1995(79.7)$ \\
\hline Former East Germany n (\%) & $509(21.3)$ \\
\hline Age & \\
\hline $\begin{array}{l}\text { Years (mean) } \\
\text { (standard deviation) (range) }\end{array}$ & 50.6 \\
\hline Age group & $(18.6)(14-90)$ \\
\hline $14-30$ years $n(\%)$ & $436(17.4)$ \\
\hline $31-60$ years $n(\%)$ & $1244(49.7)$ \\
\hline$>60$ years $n(\%)$ & $824(32.9)$ \\
\hline Domestic circumstances & \\
\hline Living with a partner $n(\%)$ & $1517(60.6)$ \\
\hline Living alone $n(\%)$ & $987(29.4)$ \\
\hline Education level &
\end{tabular}

Education leve

\begin{tabular}{l|l} 
No school qualifications $n(\%)$ & $39(1.6)$ \\
\hline Secondary general (Hauptschule) $n(\%)$ & $1102(44.0)$ \\
\hline Intermediate secondary (Realschule) n (\%) & $1004(40.1)$ \\
\hline High school (Gymnasium) n (\%) & $359(14.3)$
\end{tabular}

\begin{tabular}{l|l}
\hline Social class index & $296(11.8)$ \\
\hline Lower class $\mathrm{n}(\%)$ & $1421(56.8)$ \\
\hline Middle class $\mathrm{n}(\%)$ & $546(21.8)$ \\
\hline Upper class $\mathrm{n}(\%)$ & $241(9.6)$ \\
\hline Could not be assigned n (\%)
\end{tabular}

The goal of the present study was to ascertain retrospectively the frequency, severity and associations of maltreatment (abuse and neglect) of children and adolescents in a representative sample of the German general population. A validated questionnaire was used for this purpose. Furthermore, we investigated the possible associations of demographic variables (sex, age at time of study, social class) with maltreatment in childhood and adolescence.

\section{Material and methods Study design and sample}

A cross-sectional investigation of a randomly generated representative sample of the German general population was conducted by an independent public opinion and social research institute (USUMA, Berlin). The sample contained persons resident in 258 different places in Germany, 210 in the former West Germany and 48 in the former East Germany. Only persons at least 14 years old with adequate comprehension of written German were included.

All participants were informed about the study design and goals and signed a consent form. In the case of minors, the parents gave written consent. The study adhered to the ethical guidelines of the ICC/ESOMAR International Code of Marketing and Social Research Practice (7).

The survey was carried out in April 2010. The sample comprised 4455 persons, 2504 (56\%) of whom completed the questionnaire. The reasons for nonparticipation were:

- Refusal to be interviewed (15.6\%)

- Not at home (28.4\%).

Further details of the methods are given in eBox 1 .

\section{Survey instruments}

The following parameters (as of the time of survey) were recorded in a sociodemographic questionnaire:

- Age

- Sex

- Domestic circumstances

- Educational/occupational status

- Household income.

Social class was established using the scoring system of the German Rehabilitation Research Institutes (Reha-Forschungsverbuende):

- Educational level (no school qualifications; secondary general qualification (Hauptschule) $=1$; intermediate/ special upper secondary qualification (Realschule) $=2$; high school qualification (Gymnasium $=3$ )

- Occupational status (blue-collar worker, other $=1$; white-collar worker $=2$; self-employed $=3$ )

- Disposable monthly household net income $(<€ 1250=1 ; € 1250-2500=2 ;>€ 2500=3)$.

Participants with an overall score of 3 were coded as lower class, those with 4 to 6 points as middle class, and those who scored 7 or more as upper class (8).

Maltreatment was recorded using the 28-item short form of the Childhood Trauma Questionnaire (CTQ) (9). The CTQ is the screening instrument most widely used internationally to assess maltreatment in childhood and adolescence (up to the age of 18 years) (9). The scales of the CTQ cover abuse (with subscales for emotional, physical, and sexual abuse) and neglect (with subscales for emotional and physical neglect). An additional scale (three items) measures the tendency to minimize/deny maltreatment in childhood and adolescence. If the overall rating is "slight to moderate" or higher, maltreatment is assumed (9) (eBox 2).

Information on the psychometric properties of the CTQ can be found in eBox 3 .

\section{Statistics}

Pearson correlations among the subscales of the CTQ were calculated. Multiple logistic regression analyses 


\begin{tabular}{|c|c|c|c|c|c|}
\hline \multicolumn{6}{|c|}{ Total sample $n=2504$} \\
\hline CTQ scale & Emotional abuse & Physical abuse & Sexual abuse & Emotional neglect & Physical neglect \\
\hline \multicolumn{6}{|l|}{ Severity } \\
\hline None to minimal n (\%) & $2123(84.8)$ & $2198(87.8)$ & $2186(87.3)$ & $1259(50.3)$ & $1288(51.4)$ \\
\hline Slight to moderate n (\%) & $259(10.3)$ & $162(6.5)$ & $158(6.3)$ & $888(35.5)$ & $491(19.6)$ \\
\hline Moderate to severe n (\%) & $75(3.0)$ & $70(2.8)$ & $109(4.3)$ & $184(7.3)$ & $450(18.0)$ \\
\hline Severe to extreme $\mathrm{n}(\%)$ & $40(1.6)$ & $69(2.7)$ & $47(1.9)$ & $164(6.5)$ & $269(10.8)$ \\
\hline No information & $7(0.3)$ & $5(0.2)$ & $4(0.2)$ & $9(0.4)$ & $6(0.2)$ \\
\hline
\end{tabular}

were performed to identify any associations of demographic variables with maltreatment in childhood. The following parameters were selected as independent variables:

- Age (continuous)

- $\operatorname{Sex}(1=$ male, 2 = female $)$

- Nationality $(1=$ born in Germany, 2 = not born in Germany)

- Social class index $(1=$ lower class, $2=$ middle class, 3 = upper class)

The dependent variables were: no/minimal abuse $(=1)$ versus slight to extreme abuse $(=2)$ or no/minimal abuse $(=1)$ versus extreme abuse $(=2)$.

The internal validity of the regression models was tested by the Hosmer-Lemeshow test. If a participant failed to respond to up to $25 \%$ of the questions in the CTQ, each unanswered question was substituted by the mean value of the remaining items in the subscale concerned. If more than $25 \%$ of the questions went unanswered, that data set was excluded from analysis. All calculations were performed using the statistical software SPSS (version 17.0).

\section{Results}

\section{Demographic characteristics}

Data on 2504 persons were eligible for evaluation. Ninety-three $(3.7 \%)$ of the subjects (60 men, 33 women; mean age 41.3 years) stated that they were born outside Germany (non-German nationality) (see Table 1 for details). With regard to age and sex distribution, the sample did not differ greatly from a sample of the German general population surveyed by the Federal Statistical Office in 2007 (51\% women, mean age 49 years) (14).

\section{Frequency and severity of abuse and neglect}

Eleven participants were excluded from analysis on grounds of missing data. On the minimization/denial scale, $1581(63.1 \%)$ subjects scored 0 points, 398 (15.9\%) scored 1 point, 311 (12.4\%) scored 2, and 214 $(8.5 \%)$ scored 3 points. $15.0 \%$ of those in the total sample reported emotional abuse, $12.0 \%$ reported physical abuse, and $12.6 \%$ reported sexual abuse; $49.5 \%$ stated that they had experienced emotional neglect and $48.4 \%$, physical neglect in their childhood and/or adolescence. Severe emotional abuse in childhood and adolescence was reported by $1.6 \%$ of the total sample, severe physical abuse by $2.8 \%$, and severe sexual abuse by $1.9 \%$. Severe emotional neglect in childhood and adolescence was stated by $6.6 \%$ and severe physical neglect by $10.8 \%$ (Table 2).

Of the 2493 responders whose data were eligible for analysis, $796(31.8 \%)$ reported no abuse or neglect of any kind, $690(27.7 \%)$ reported one type of abuse or neglect, $591(23.7 \%)$ reported two types, 208 (8.3\%) reported three types, $115(4.6 \%)$ reported four types, and $93(3.7 \%)$ reported all five categories of abuse and neglect.

$2131(85.5 \%)$ responders reported no severe abuse or neglect of any kind, while $222(8.9 \%)$ reported one type of severe abuse or neglect, $82(3.3 \%)$ reported two types, $35(1.4 \%)$ reported three types, $20(0.8 \%)$ reported four types, and $3(0.1 \%)$ reported severe abuse and neglect in all five categories.

\section{Correlations among the different types of maltreatment}

All forms of maltreatment were significantly correlated $(p<0.0001)$. The strongest correlations were those between emotional abuse and physical abuse $(r=0.67)$ and between emotional neglect and physical neglect $(\mathrm{r}=0.59)$. The weakest correlations were those between sexual abuse and emotional neglect $(r=0.25)$ and between sexual abuse and physical neglect $(\mathrm{r}=0.33)$.

\section{Predictors of any maltreatment}

Lower social class was a predictor for emotional and physical abuse and for emotional and physical neglect. Middle class was a risk factor for physical abuse and for emotional and physical neglect. Female sex was a predictor for sexual abuse. Higher age at the time of the survey and birth outside Germany predicted physical neglect (Table 3). 


\section{Predictors of severe maltreatment}

Belonging to the lower or middle social classes predicted severe emotional and physical abuse and severe emotional and physical neglect. Female sex was a predictor for severe sexual abuse. Birth outside Germany predicted severe emotional and physical abuse and severe physical neglect. Higher age at the time of the survey predicted severe emotional and physical neglect (Table 4).

The logistic regression analysis models were significant. With the sole exception of physical abuse of any degree, the p-values of the Hosmer-Lemeshow test were above the level of significance.

\section{Discussion}

\section{Comparison with other studies}

We compared our results with the findings of other studies with regard to the following points:

- Prevalence of maltreatment

- Severity and correlations of maltreatment

- Groups at risk of maltreatment.

\section{Prevalence of maltreatment}

Studies using the CTQ-In a population-based study conducted in the USA in 2003, 775 persons (507 women, 268 men) aged between 18 and 65 years were interviewed by telephone. The rates of at least mild maltreatment for women (men in parentheses) were as follows:

- Physical abuse $13.8 \%$ (17.1\%)

- Sexual abuse $10.4 \%(6.7 \%)$

- Emotional neglect $25.7 \%$ (31.3\%).

Emotional neglect was less frequent than in our study, while the rates of physical and sexual abuse were similar (15).

Studies involving German population samplesBecause of differences in the definitions of maltreatment, our study is not fully comparable with the one published by Wetzels in 1998 (5). In the latter, 74.9\% of the 3289 subjects stated they had experienced physical violence during childhood and $10.6 \%$ reported physical maltreatment at the hands of their parents. Physical maltreatment was defined as any act going beyond the parents' right to discipline their children as defined in law. Experience of sexual abuse (with physical contact) before the age of 16 was reported by $8.6 \%$ of the women and $2.8 \%$ of the men.

In 2005 , a representative sample of 814 people between 60 and 75 years of age were surveyed by means of the Munich Composite International Diagnostic Interview. Traumatic physical violence in childhood was reported by $12.9 \%$ of the men and $5.1 \%$ of the women, rape by $0.3 \%$ of the men and $1.5 \%$ of the women (16). The prevalence of sexual abuse found by Glaesmer et al. (16) corresponds to that in the present study.

In a survey of 91 women born between 1895 and $1936,18 \%$ reported sexual abuse below the age of 13 years and $21 \%$ stated they had been sexually abused between the ages of 13 and 21. Eight percent of the sexually abused women reported that sexual inter- course had been forced upon them. In 37\% of these cases the perpetrator was a stranger and in $15 \%$ of cases a family member (17). The frequency of severe sexual abuse was lower in the present study.

Studies in the USA-Emotional and physical neglect were also the most frequent forms of childhood maltreatment in an American study, which were reported by up to $50 \%$ of the respondents (18).

\section{Severity of maltreatment / correlations among types of maltreatment}

The results of our study confirm the conclusion of a review from the USA, namely that mild forms of maltreatment are more frequent than severe forms (19).

Our finding of significant correlations of all forms of maltreatment with one another points to the need to see maltreatment in context: in conditions of unfavorable socialization, children may suffer multiple forms of maltreatment. In a survey of 8667 citizens covered by one health insurance provider, $34.7 \%$ reported more than one kind of maltreatment (personal experience of physical and/or sexual abuse or physical maltreatment of their mother while they were present) (20). Wetzels found that $64.3 \%$ of the victims of sexual abuse (with physical contact) also suffered more frequent or more intensive physical violence at the hands of their parents (5).

\section{Groups at risk of maltreatment}

In agreement with Lampe's review of European studies (6), we found that sexual abuse was reported more frequently by women than by men. In contrast to the majority of studies reviewed by Lampe (probands: school students, college students, members of the general population), where experience of physical violence was reported more often for boys than for girls, we found no difference between the sexes in this regard. We agreed with Wetzels (5) in finding no association between social class and sexual abuse. A recent British populationbased survey of 7353 persons also found no association between severe sexual abuse in childhood $(2.9 \%$ for women and $0.8 \%$ for men) and social class (21).

Both Wetzels' study conducted in 1992 (5) and the present investigation revealed an inverse relationship between physical maltreatment and social class. The 1992 study recorded the socioeconomic status of the parents in the respondent's childhood, while we noted the respondent's current socioeconomic status. The class indexes used in our study have ordinal scales and show a class gradient. The lower rates of physical abuse and neglect for children from higher social classes can be explained by a more caring home environment in higher income, better educated segments of the population and a more restrictive style of upbringing in socially disadvantaged groups (22). The negative association between physical and emotional neglect and abuse in childhood and social class index can be explained by the following two hypotheses:

- Given that people tend to have the same social status as their parents (e1), it is likely that the 
Logistic regression of the predictors of any maltreatment (slight to extreme) in childhood and adolescence

\begin{tabular}{|c|c|c|c|c|c|}
\hline Dependent variable ${ }^{* 1}$ & $\begin{array}{l}\text { Independent } \\
\text { variables }{ }^{3}\end{array}$ & Odds ratio (OR) & $\begin{array}{l}95 \% \text { confidence } \\
\text { interval }\end{array}$ & B & p-value \\
\hline \multirow{5}{*}{$\begin{array}{l}\text { Emotional abuse } \\
(n=334)^{*^{2}}\end{array}$} & Sex & 1.004 & $0.79-1.27$ & 0.004 & 0.97 \\
\hline & Age & 0.99 & $0.98-1.002$ & -0.005 & 0.15 \\
\hline & Nationality & 1.10 & $0.59-2.02$ & 0.09 & 0.77 \\
\hline & Lower class & 2.25 & $1.51-3.36$ & 0.81 & $<0.001$ \\
\hline & Middle class & 1.35 & $0.99-1.82$ & 0.30 & 0.05 \\
\hline \multirow{5}{*}{$\begin{array}{l}\text { Physical abuse } \\
(n=272)^{\star 2}\end{array}$} & Sex & 0.84 & $0.65-1.09$ & -0.17 & 0.19 \\
\hline & Age & 1.004 & $0.99-1.01$ & 0.004 & 0.26 \\
\hline & Nationality & 1.50 & $0.80-2.79$ & 0.40 & 0.20 \\
\hline & Lower class & 4.055 & $2.57-6.39$ & 1.40 & $<0.001$ \\
\hline & Middle class & 1.94 & $1.32-2.84$ & 0.66 & 0.001 \\
\hline \multirow{5}{*}{$\begin{array}{l}\text { Sexual abuse } \\
(n=287)^{\star 2}\end{array}$} & Sex & 1.65 & $1.27-2.14$ & 0.50 & $<0.001$ \\
\hline & Age & 1.00 & $0.99-1.01$ & 0.00 & 0.95 \\
\hline & Nationality & 1.78 & $0.99-3.20$ & 0.58 & 0.50 \\
\hline & Lower class & 1.50 & $0.96-2.32$ & 0.40 & 0.07 \\
\hline & Middle class & 1.20 & $0.87-1.64$ & 0.18 & 0.26 \\
\hline \multirow{5}{*}{$\begin{array}{l}\text { Emotional neglect } \\
(\mathrm{n}=628)^{* 2}\end{array}$} & Sex & 0.89 & $0.75-1.05$ & -0.12 & 0.18 \\
\hline & Age & 0.997 & $0.99-1.002$ & -0.003 & 0.30 \\
\hline & Nationality & 1.21 & $0.76-1.90$ & 0.19 & 0.42 \\
\hline & Lower class & 2.11 & $1.56-2.85$ & 0.75 & $<0.001$ \\
\hline & Middle class & 1.37 & $1.12-1.68$ & 0.32 & 0.002 \\
\hline \multirow{5}{*}{$\begin{array}{l}\text { Physical neglect } \\
(n=703)^{\star 2}\end{array}$} & Sex & 0.85 & $0.71-1.006$ & -0.17 & 0.06 \\
\hline & Age & 1.03 & $1.02-1.03$ & 0.03 & $<0.001$ \\
\hline & Nationality & 1.76 & $1.10-2.81$ & 0.57 & 0.02 \\
\hline & Lower class & 2.45 & $1.78-3.35$ & 0.89 & $<0.001$ \\
\hline & Middle class & 1.74 & $1.41-2.15$ & 0.56 & $<0.001$ \\
\hline
\end{tabular}

${ }^{* 1}$ Dependent variable: no abuse (reference category = no/minimal abuse; OR = 1; coding = 1) vs. abuse (slight to extreme abuse; coding = 2) ${ }^{* 2}$ Discrepancies from Table 1 with regard to the frequencies of the different types of maltreatment arise from the exclusion of persons with incomplete data on demographic characteristics (social class index) from regression analysis. ${ }^{*} 3$ The independent variables are coded as follows: age (continuous), sex ( $1=$ male, $2=$ female), nationality ( $1=$ born in Germany, $2=$ not born in Germany) and social class index ( $1=$ lower class, $2=$ middle class, $3=$ upper class $)$

current social class of some members of the sample corresponds to their family's position on the social scale during their childhood and adolescence.

- Maltreatment during childhood is a risk factor for mental disorders in all age groups (e2). Mental health problems in adolescence increase the likelihood of education ending at a low level (e3). Mental disorder in adulthood elevates the risk of unemployment and lowering of social status (e4). The higher rates of childhood maltreatment among those whose current social status is low may be explained by the moderating variable "mental disorder".
The higher rate of childhood physical neglect in the elderly can be attributed to deprivation during and after World War II.

\section{Limitations of the study}

The response rate of $56 \%$ was somewhat lower than those of earlier surveys (23). No further analyses were possible on grounds of data protection; therefore, it could not be established whether respondents and nonrespondents differed with regard to clinical and sociodemographic characteristics.

The potential sources of error in the retrospective recording of childhood experiences include incorrect attribution, suggestibility, and distortion owing to 
Logistic regression of the predictors of extreme maltreatment in childhood and adolescence

\begin{tabular}{|c|c|c|c|c|c|}
\hline Dependent variable ${ }^{* 1}$ & $\begin{array}{l}\text { Independent } \\
\text { variables }{ }^{* 3}\end{array}$ & Odds ratio (OR) & $\begin{array}{l}95 \% \text { confidence } \\
\text { interval }\end{array}$ & B & p-value \\
\hline \multirow{5}{*}{$\begin{array}{l}\text { Severe emotional abuse } \\
(n=32)^{*^{2}}\end{array}$} & Sex & 1.65 & $0.79-3.45$ & 0.50 & 0.18 \\
\hline & Age & 0.98 & $0.96-1.00$ & -0.02 & 0.09 \\
\hline & Nationality & 3.73 & $1.23-11.25$ & 1.32 & 0.02 \\
\hline & Lower class & 0.13 & $0.03-0.53$ & -2.02 & 0.004 \\
\hline & Middle class & 0.39 & $0.16-0.93$ & -0.94 & 0.03 \\
\hline \multirow{5}{*}{$\begin{array}{l}\text { Severe physical abuse } \\
(n=58)^{\star^{2}}\end{array}$} & Sex & 0.98 & $0.57-1.67$ & -0.03 & 0.93 \\
\hline & Age & 1.00 & $0.99-1.01$ & 0.00 & 0.96 \\
\hline & Nationality & 2.83 & $1.06-7.59$ & 1.04 & 0.04 \\
\hline & Lower class & 0.08 & $0.03-0.25$ & 2.51 & $<0.0001$ \\
\hline & Middle class & 0.26 & $0.15-0.48$ & 1.33 & $<0.0001$ \\
\hline \multirow{5}{*}{$\begin{array}{l}\text { Severe sexual abuse } \\
(n=37)^{\star 2}\end{array}$} & Sex & 4.15 & $1.80-9.59$ & 4.15 & 0.001 \\
\hline & Age & 0.99 & $0.98-1.02$ & -0.004 & 0.69 \\
\hline & Nationality & 2.33 & $0.53-10.26$ & 0.85 & 0.26 \\
\hline & Lower class & 0.32 & $0.09-1.12$ & -1.13 & 0.07 \\
\hline & Middle class & 0.63 & $0.26-1.56$ & -0.46 & 0.32 \\
\hline \multirow{5}{*}{$\begin{array}{l}\text { Severe emotional neglect } \\
(n=151)^{* 2}\end{array}$} & Sex & 1.03 & $0.73-1.46$ & 0.03 & 0.89 \\
\hline & Age & 0.98 & $0.98-0.99$ & -0.01 & 0.02 \\
\hline & Nationality & 1.36 & $0.58-3.12$ & 0.31 & 0.48 \\
\hline & Lower class & 0.29 & $0.16-0.51$ & -1.25 & $<0.0001$ \\
\hline & Middle class & 0.43 & $0.26-0.68$ & -0.86 & $<0.0001$ \\
\hline \multirow{5}{*}{$\begin{array}{l}\text { Severe physical neglect } \\
(n=245)^{* 2}\end{array}$} & Sex & 0.87 & $0.65-1.17$ & -0.14 & 0.36 \\
\hline & Age & 1.03 & $1.02-1.04$ & 0.03 & $<0.0001$ \\
\hline & Nationality & 2.02 & $0.99-4.14$ & 0.71 & 0.05 \\
\hline & Lower class & 0.14 & $0.08-2.43$ & -1.96 & $<0.0001$ \\
\hline & Middle class & 0.43 & $0.30-0.63$ & -0.84 & $<0.0001$ \\
\hline
\end{tabular}

${ }^{* 1}$ Dependent variable: no abuse (reference category $=$ no/minimal abuse; $\mathrm{OR}=1 ;$ coding $=1$ ) vs. extreme abuse (coding $=2$ ) ${ }^{*}$ Discrepancies from Table 1 with regard to the frequencies of the different types of maltreatment arise from the exclusion of persons with incomplete data on demographic characteristics (social class index) from regression analysis. ${ }^{* 3}$ The independent variables are coded as follows: age (continuous), sex ( $1=$ male, $2=$ female), nationality ( 1 = born in Germany, 2 = not born in Germany) and social class index ( $1=$ lower class, 2 = middle class, $3=$ upper class $)$

subjective logic. The possibility of false-negative statements due to unconscious (memory suppression) or conscious (shame) motives has been discussed exhaustively in the literature (24). In various studies the proportion of adults who recalled a documented instance of sexual abuse in childhood lay between $62 \%$ and $81 \%$ (25). The relatively high number of respondents with the highest possible score on the minimization/denial scale $(8.5 \%)$ indicates a possible tendency towards denial by some members of our sample. Moreover, some people who would be classified as having suffered maltreatment on objective criteria do not view themselves as maltreated-not in the sense of intentional dissimulation, but because they grew up in an environment where maltreatment of children was the rule. This distorted self-perception cannot be detected with the CTQ, only with structured interviews on traumatization in childhood (10). The CDC's broad definitions of abuse and neglect and the CTQ's low threshold for mild to moderate abuse continue to lead to high reporting of low-grade maltreatment in childhood.

The number of siblings was not recorded. The higher number of siblings in lower-class families and among older respondents may have contributed to the higher rates of neglect in these two groups.

\section{Conclusion}

The retrospectively reported frequencies and correlations of the various forms of maltreatment in 
childhood and adolescence in this survey of a representative sample of the German population correspond to the results of a population-based German study conducted in 1992 and recent investigations in the USA. Physical and emotional neglect are less frequent in younger generations than among those whose childhood and adolescence fell during World War II and the years immediately thereafter.

\section{Conflict of interest statement}

Dr. Häuser has received honoraria for non-product-related lectures from El Lilly, Janssen-Cilag, Mundipharma, and Pfizer and reimbursement of travel costs from Eli Lilly.

Ms Schmutzer, Prof. Brähler und Dr. Glaesmer declare that no conflict of interest exists.

Manuscript received on 12 0ctober 2010, revised version accepted on 14 February 2011.

Translated from the original German by David Roseveare.

\section{REFERENCES}

1. World Health Organisation: World Report on violence and health. Genf: World Health Organisation 2002.

2. Leeb RT, Paulozzi L, Melanson C, Simon T, Arias I: Child Maltreatment Surveillance: Uniform Definitions for Public Health and Recommended Data Elements, Version 1.0. Atlanta (GA): Centers for Disease Control and Prevention, National Center for Injury Prevention and Control 2008.

3. Landgraf M, Zahner L, Nickel P, Till H, Keller A, Geyer C, Schwanitz N, Gausche R, Schmutzer G, Brähler E, Kiess W: Kindesmisshandlung. Soziodemografie, Ausmaß und medizinische Versorgung Retrospektive Analyse von 59 Patienten/-innen. Monatsschr Kinderheilk 2010; 158: 149-56.

4. Finkelhor D: The international epidemiology of child sexual abuse. Child Abuse Negl. 1994; 18: 409-17.

5. Wetzels P: Gewalterfahrungen in der Kindheit. Sexueller Missbrauch, körperliche Misshandlung und deren langfristige Konsequenzen. Baden-Baden: Nomos 1998.

6. Lampe A: Die Prävalenz von sexuellem Missbrauch, körperlicher Gewalt und emotionaler Vernachlässigung in der Kindheit in Europa. Z Psychosom Med Psychother 2002; 48: 370-80.

7. Verbände der Deutschen Markt- und Sozialforschung. Erklärung für das Gebiet der Bundesrepublik Deutschland zum ICC/ESOMAR Internationalen Kodex für die Markt- und Sozialforschung: www. adm-ev.de/pdf/Erklaerung_2008.pdf

8. Deck E, Röckelein E: Zur Erhebung soziodemographischer und sozialmedizinischer Indikatoren in den rehabilitationswissenschaftlichen Forschungsverbünden. In: Verband Deutscher Rentenver- sicherungen. Förderschwerpunkt Rehabilitationswissenschaften. Empfehlungen der Arbeitsgruppe „Generische Methoden“, „Routinedaten“ und „Rehaökonomie“. Frankfurt Main1999; 85-102.

9. Bernstein DP, Stein JA, Newcomb MD, et al.: Development and validation of a brief screening version of the Childhood Trauma Questionnaire. Child Abuse Negl 2003; 27: 169-90.

10. Wingenfeld K, Spitzer C, Mensebach C, et al.: Die deutsche Version des Chlidhood Traum Questionnaire (CTQ): Erste Befunde zu den psychometrischen Kennwerten. Psychother Psych Med 2010; 60: 424-50.

11. Wulff H: Childhood Trauma Questionnaire. Entwicklung einer deutschsprachigen Version und Überprüfung bei psychiatrisch - psychotherapeutisch behandelten Patienten. Inauguraldissertation zur Erlangung der Doktorwürde der Universität zu Lübeck. Medizinische Fakultät: Lübeck 2006.

12. Bernstein DP, Fink L, Handelsman L, Foote J, Foote J, Lovejoy M: Initial reliability and validity of a new retrospective measure of child abuse and neglect. Am J Psychiatry 1994; 151: 1132-6.

13. Bernstein DP, Ahluvalia T, Pogge D, Handelsman L: Validity of the Childhood Trauma Questionnaire in an adolescent psychiatric population. J Am Acad Child and Adolesc Psychiat 1995; 36: 340-8.

14. Statistisches Bundesamt Deutschland: Statistisches Jahrbuch 2008. www.destatis.de/jetspeed/portal/cms/Sites/destatis/SharedContent/ Oeffentlich/Al/IC/Publikationen/Jahrbuch/Bildung,property=file.pdf

15. Thombs BD, Bernstein DP, Ziegelstein RC, Scher CD, Forde DR, Walker EA, Stein MB: An evaluation of screening questions for childhood abuse in 2 community samples: implications for clinical practice. Arch Intern Med 2006; 166: 2020-6.

16. Glaesmer H, Gunzelmann T, Braehler E, Forstmeier S, Maercker A: Traumatic experiences and post-traumatic stress disorder among elderly Germans: results of a representative population-based survey. Int Psychogeriatr 2010; 22: 661-70.

17. von Sydow K: Psychosexuelle Entwicklung im Lebenslauf. Eine biographische Studie bei Frauen der Geburtsjahrgänge 1895-1936. Regensburg: S. Roderer 1991

18. US Department of Health and Human Services. Child maltreatment 2004. Washington: US Government Printing Office 2004.

19. Emery RE, Laumann-Billings L: An overview of the nature, causes, and consequences of abusive family relationships. Toward differentiating maltreatment and violence. Am Psychol 1998; 53: 121-35.

20. Edwards VJ, Holden GW, Felitti VJ, Anda RF: Relationship between multiple forms of childhood maltreatment and adult mental health in community respondents: results from the adverse childhood experiences study. Am J Psychiatry. 2003; 160: 1453-60.

21. Bebbington PE, Jonas S, Brugha T, Meltzer H, Jenkins R, Cooper C King M, McManus S: Child sexual abuse reported by an English national sample: characteristics and demography. Soc Psychiatry Psychiatr Epidemiol 2011; 46: 255-62.

KEY MESSAGES

- In the year 2010, a representative sample of the German population comprising 2504 persons aged between 14 and 90 years completed the Childhood Trauma Questionnaire, an instrument used to measure maltreatment in childhood and adolescence.

- Severe emotional abuse in childhood and/or adolescence was reported by $1.6 \%$ of the total sample, severe physical abuse by $2.8 \%$, severe sexual abuse by $1.9 \%$, severe emotional neglect by $6.6 \%$, and severe physical neglect by $10.8 \%$.

- Being lower class or middle class predicted severe emotional abuse, severe physical abuse, severe emotional neglect, and severe physical neglect.

- Female sex was a predictor of severe sexual abuse.

- The retrospectively reported frequencies of maltreatment in childhood and adolescence in this survey correspond to the results of a population-based German study conducted in 1992. 
22. Lampert T, Schenk L, Stolzenberg H: Konzeptualisierung und Operationalisierung sozialer Ungleichheit im Kinder- und Jugendgesundheitssurvey. Gesundheitswesen 2002; 64: 48-52.

23. Häuser W, Schmutzer G, Glaesmer H, Brähler H: Prävalenz und Prädiktoren von Schmerzen in mehreren Körperregionen. Ergebnisse einer repräsentativen deutschen Bevölkerungsstichprobe. Schmerz 2009; 23: 461-70.

24. Hardt J, Rutter M: Validity of adult retrospective reports of adverse childhood experiences: review of the evidence. J Child Psychol Psychiatry 2004; 45: 260-73.

25. Goodman GS, Ghetti S, Quas JA, et al.: A prospective study of memory for child sexual abuse: new findings relevant to the repressedmemory controversy. Psychol Sci 2003; 14: 113-8.

Corresponding author

PD Dr. med. Winfried Häuser

Klinik für Innere Medizin I (Gastroenterologie, Hepatologie, Stoffwechsel- und Infektionskrankheiten, Psychosomatik)

Klinikum Saarbrücken gGmbH

Winterberg 1

66119 Saarbrücken, Germany

whaeuser@klinikum-saarbruecken.de

(2) For eReferences please refer to: www.aerzteblatt-international.de/ref1711

eBoxes available at:

www.aerzteblatt-international.de/11m0287 


\section{ORIGINAL ARTICLE}

\section{Maltreatment in Childhood and Adolescence}

Results From a Survey of a Representative Sample of the German Population

Winfried Häuser, Gabriele Schmutzer, Elmar Brähler, Heide Glaesmer

\section{eReferences}

e1. Björklund A, Jäntti M, Solon G: Nature and nurture in the intergenerational transmission of socioeconomic status: evidence from Swedish children and their biological and rearing parents. Journal of Economic Analysis \& Policy 2007; 7 www.bepress.com/be jeap/vol7/iss2/art4 (elektronischer Zugriff am 15.01.2011)

e2. Wilson DR: Health consequences of childhood sexual abuse. Perspect Psychiatr Care 2010; 46: 56-64.

e3. Jonsson U, Bohman H, Hjern A, von Knorring L, Olsson G, von Knorring AL: Subsequent higher education after adolescent depression: a 15-year follow-up register study. Eur Psychiatry 2010; 25: $396-401$.

e4. Saraceno B, Levav I, Kohn R: The public mental health significance of research on socio-economic factors in schizophrenia and major depression. World Psychiatry 2005; 4: 181-5. 


\section{Maltreatment in Childhood and Adolescence}

Results From a Survey of a Representative Sample of the German Population

Winfried Häuser, Gabriele Schmutzer, Elmar Brähler, Heide Glaesmer

\section{eBOX 1}

\section{Details of method}

The study was financed by funds from the Department of Medical Psychology and Medical Sociology, University of Leipzig.

The trained interviewers $(n=232)$ received written instructions for this project. The target person was given a structured questionnaire to be filled in personally in the presence of (but not influenced by) the interviewer. In the interests of anonymity the participants had the opportunity to return the completed questionnaire to the interviewer in a sealed envelope. These envelopes were opened only after they had been returned to the institute.

The target households were chosen at random using the random-route procedure with a defined starting address. The interviewer was instructed to start at a specific house in a particular street. Every third household was then identified and contacted with goal of conducting an interview. To this end the selected addresses were entered in a list. For each individual household, the names of all members aged 14 years or more were entered in a table on the address list and a target person was chosen randomly. A maximum of three attempts were made to contact this person directly. No messages were left.

When contacted, the target person was told there were various questionnaires to fill in, but not informed of the specific focus of the study. The interviewer answered any comprehension questions posed by the target person during completion of the questionnaires.

The reasons for non-participation were as follows:

- No-one found at home on any of three visits (11.1\%)

- Household refused to give information (12.8\%)

- Target person not found at home on any of three visits $(2.8 \%)$

- Target person away from home $(1.1 \%)$

- Target person sick or unable to comprehend the content of the questionnaires $(1.1 \%)$

- Target person refused to participate (15.6\%).

The interviews were checked for completeness on return of the questionnaires to the institute. Before data capture, a coder checked for correct filtering. Specific routines were used for data capture. Next, error-seeking routines were run on the data. The data were adjusted on the basis of the original questionnaires. The interviewers carried out written controls using pre-addressed postcards. A total of $39.6 \%$ of the interviews were randomly selected for written control. The response rate was $51.2 \%$, and all responders confirmed that the interviewer had worked correctly. 


\section{German version of the Childhood Trauma Questionnaire}

The proband rates the occurrence of maltreatment on a five-point scale from "Never" [1] to "Very often" [5]. The score on each maltreatment subscale ranges from 5 points (no maltreatment in childhood and adolescence) to 25 points (extreme maltreatment experienced).

\section{Anleitung:}

Diese Fragen befassen sich mit einigen Ihrer Erfahrungen während Ihrer Kindheit und Jugend (bis zum 18. Lebensjahr).

Auch wenn die Fragen sehr persönlich sind, versuchen Sie bitte, sie so ehrlich wie möglich zu beantworten.

Markieren Sie dazu bitte für jede Frage die Zahl, die am besten beschreibt, wie Sie sich fühlen, mit einem Kreuz oder einem Kreis.

\section{Fragebogen: Während meiner Kindheit und Jugend ....}

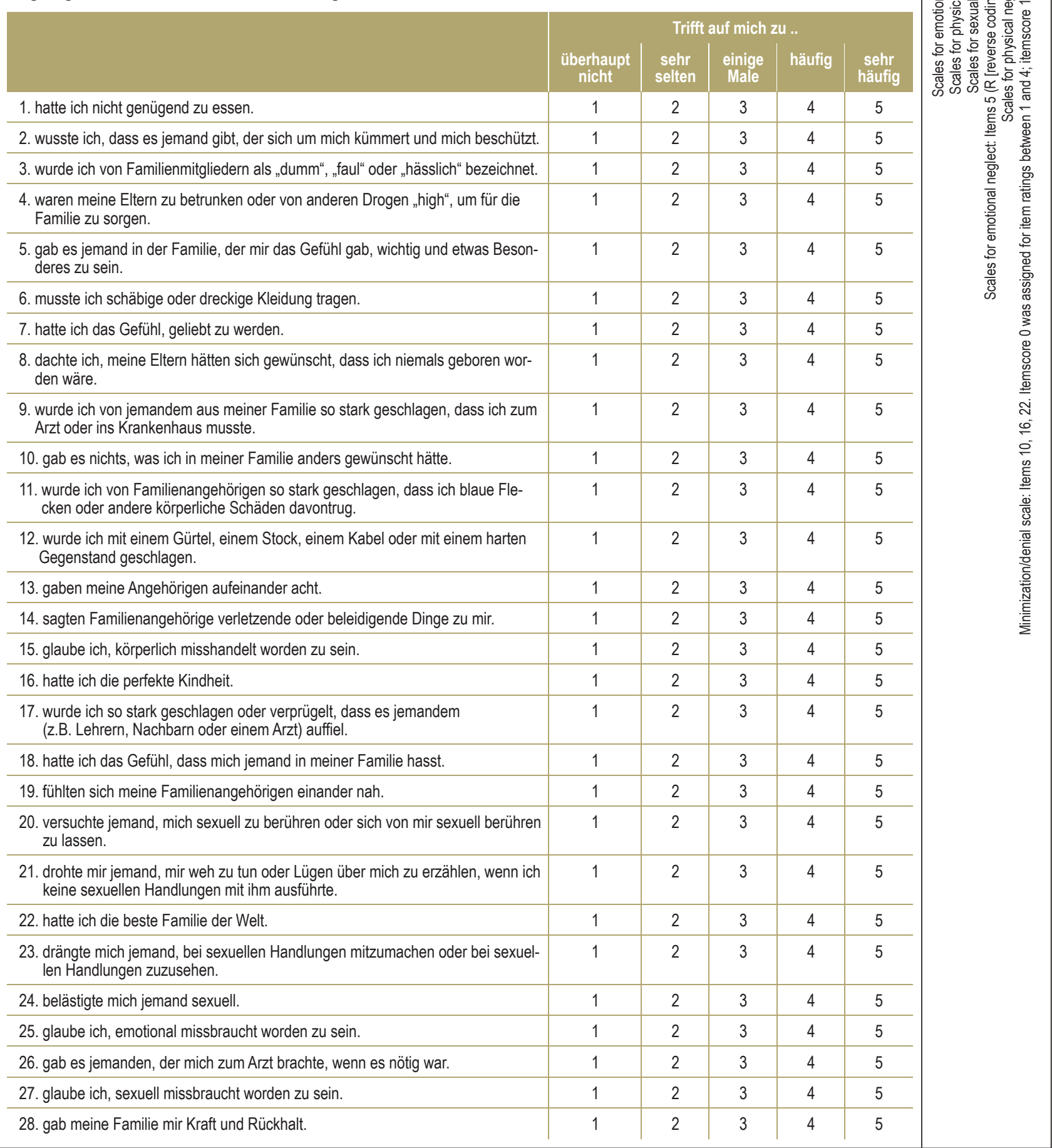


Assessment of the severity of maltreatment (9)

\begin{tabular}{l|c|c|c|c} 
& None to minimal & Slight to moderate & Moderate to severe & Severe to extreme \\
\hline Emotional abuse & $5-8$ & $9-12$ & $13-15$ & $16-25$ \\
\hline Physical abuse & $5-7$ & $8-9$ & $10-12$ & $13-25$ \\
\hline Sexual abuse & 5 & $6-7$ & $8-12$ & $13-25$ \\
\hline Emotional neglect & $5-9$ & $10-14$ & $15-17$ & $18-25$ \\
\hline Physical neglect & $5-7$ & $8-9$ & $10-12$ & $13-25$
\end{tabular}




\section{eBOX 3}

\section{Psychometric properties of the Childhood Trauma Questionnaire}

The short form of the Childhood Trauma Questionnaire (CTQ) was translated into German, checked by back-translation, and validated on samples from German departments of psychiatry and psychotherapy $(10,11)$. The internal consistency of the subscales lay between 0.62 and 0.96 (9). As a measure of test-retest reliability at a median interval of 6 weeks, the intraclass coefficient was 0.77 for the CTQ as a whole and 0.58 to 0.81 for the subscales (10).

The results of the CTQ correlated moderately with those of semistructured interviews (from 0.43 for physical and emotional abuse to 0.57 for sexual abuse) (12). Furthermore, the results of the CTQ correlated adequately with ratings by psychotherapists (from 0.42 for physical neglect to 0.72 for sexual abuse) (13). 